\title{
Apresentação do Dossiê "Educação a Distância (EaD) e o uso das tecnologias na educação - qualidade, tendências e práticas"
}

\author{
Daniela da Costa Britto Pereira Lima \\ Kátia Morosov Alonso ${ }^{2}$
}

DOI: http://dx.doi.org/10.20435/serie-estudos.v24i51.1307

Tanto no Brasil quanto em outros países, a Educação a Distância (EaD) tem sido objeto de estudos e pesquisas, tendo como foco diversos vieses: políticas públicas, planejamento, qualidade, oferta, uso de tecnologias, processo ensino-aprendizagem, interação e mediação, acompanhamento discente, dentre tantos outros. Ultimamente, estudos internacionais (SHERMAN; CRUM; BEATY, 2010; HAFEEZ; GUJJAR; NOREEN, 2014; RAJESH, 2015) têm relacionado que a oferta da EaD com o uso de tecnologias de informação e comunicação, ou tecnologias digitais de informação e comunicação, tem sido um elemento inovador na educação superior quando do seu uso, seja em cursos totalmente a distância ou em cursos híbridos.

Alonso (2014) destaca que, desde os primeiros passos na implementação de projetos e programas de formação que se utilizam da EaD em seu desenvolvimento no Brasil, não houve proposição para que fossem analisados/avaliados os seus resultados que tinham por objetivos o acesso à educação superior e a sua democratização. Os estudos no campo de EaD são, em sua maioria, conforme apontado por Alonso (2010), fragmentados, focados em experiências de uso de tecnologias da informação e comunicação (TIC) e, mais recentemente, no uso dos denominados ambientes virtuais de aprendizagem (AVA). Por consequência, as pesquisas sobre a EaD são, ainda, bastante localizadas, sem que se tenha constituído um campo robusto seja em sua sustentação teórica quanto metodológica, conforme observado por Zawachi-Richter, Backer e Vogt (2009).

Alonso (2010) complementa ainda que, em dossiês, periódicos e outros

\footnotetext{
${ }^{1}$ Universidade Federal de Goiânia (UFG), Goiânia, Goiás, Brasil.

2 Universidade Federal de Mato Grosso (UFMT), Cuiabá, Mato Grosso, Brasil.
} 
meios que divulgam pesquisas no campo educacional, é possível observar tendências na implementação da EaD no Brasil. Alonso (2010), Dourado (2008), entre outros, atentaram para o caráter quantitativista, privatista e de novos nichos de mercado relacionados à expansão da educação superior. Por outro lado, Peixoto (2009), Lima, Faria e Desidério (2013) discutem e problematizam o trabalho docente de forma intensificada e a formação aligeirada por meio da EaD.

Assim, a partir de pesquisa realizada pelas organizadoras com o apoio da Coordenação de Aperfeiçoamento de Pessoal de Nível Superior (Capes), da Fundação de Amparo à Pesquisa do Estado de Goiás (Fapeg) e do Conselho Nacional de Desenvolvimento Científico e Tecnológico (CNPq), o presente dossiê pretende debater a temática em voga no sentido de se avançar em relação às tendências antes mencionadas com contribuições de autores que possuem vínculos institucionais do Brasil e do exterior (da Espanha e Portugal). Nesse sentido, pretende-se apresentar estudos e pesquisas que tratem da EaD e do uso das tecnologias na educação que indiquem movimentos e dinâmicas, diferentes utilizações ou desenvolvimento dela - EaD- com qualidade tanto no Brasil quanto em outros países.

Para abrir o dossiê, temos o estudo intitulado "Tecnología y Educación: en busca de una pedagogía liberadora frente a la neocolonización digital", da professora pesquisadora Cláudia Prioste, que discute novas formas de opressão e colonização que ocorrem na era digital, confrontando determinadas relações com os pressupostos teóricos de Paulo Freire. A partir de pesquisas empíricas realizadas pela pesquisadora nos últimos dez anos, tratando dos efeitos educacionais do uso das tecnologias de informação e comunicação por adolescentes e crianças brasileiras, apresentam-se proposições, buscando, de forma inovadora, estimular novos posicionamentos pedagógicos.

A pesquisa de Jhonny David Echalar, Daniela da Costa Britto Pereira Lima e Kátia Morosov Alonso, "Produções Científicas do GT 16 Educação e Comunicação da ANPEd entre 2011 e 2017: contribuições da análise bibliométrica para qualificação da área", busca, por meio de levantamento bibliográfico nos trabalhos publicados nos Anais dos eventos nacionais e regionais da Associação Nacional de Pesquisa em Educação (ANPEd), compreender as perspectivas teóricas mais utilizadas. Os dados indicam que existe maior utilização de referências do campo da Comunicação se comparada à da Educação. 
Apresentação do Dossiê "Educação a Distância (EaD) e o uso das tecnologias na educação - qualidade, tendências e práticas"

Anabel Galán-Mañas, pesquisadora da Espanha, apresenta em seu artigo "Blended learning en la universidad. Denominaciones y modelos" o blended learning como um modelo a ser utilizado no processo ensino-aprendizagem, com o uso de tecnologias e metodologias ativas, características essas que poderão desenvolver as "destrezas" solicitadas à nova geração formada na universidade. São apresentados modelos e principais características dos elementos que o compõem.

De maneira contundente, Isamélia Santos Guimarães Carvalho, José Tejada e Katia Verónica Pozos Pérez, também pesquisadores da Espanha, em seu artigo "Formación docente para la educación a distancia: la construcción de las competencias docentes digitales", analisam as competências digitais do perfil do professor da educação superior em seus diferentes níveis com o objetivo de estabelecer as necessidades formativas e planejar uma formação docente para os referidos professores de modo a superar práticas ainda conservadoras.

Num esforço de interlocução entre pesquisadores do Brasil e Portugal, a pesquisa "Competências digitais e as demandas da sociedade contemporânea: diagnóstico e potencial para formação de professores do Ensino Superior da Bahia", de Mary Valda Sales, José António Marques Moreira e Márcia Rangel buscam mapear e analisar as relações atuais existentes entre os campos investigativos da prática pedagógica dos professores, das tecnologias e o "domínio" das tecnologias para formação no contexto universitário, para que possam definir diferentes trilhas de aprendizagem em função do diagnóstico realizado.

No artigo "Tecnologias digitais na educação: tecendo novas experiências formativas com professores da educação básica", Sandra Virgínia Correia de Andrade Santos e Simone Lucena discutem a formação de professores como ponto de partida para a apropriação e fluência dos dispositivos digitais em contextos educativos, partindo do princípio de que, para o professor se reinventar, necessita de novas experiências formativas. Os resultados prévios da pesquisa em andamento demonstram, porém, a necessidade de se considerar "dilemas docentes" nos processos formativos para que vivenciem novos processos e, assim, potencializem o uso das tecnologias em sala de aula.

Silvana Aparecida Guietti e Maria Luisa Furlan Costa apresentam resultado de estudo sobre "Análise dos efeitos da política Sistema Universidade Aberta do Brasil na perspectiva dos egressos da Universidade Estadual de Maringá", do curso de Pedagogia, na modalidade de EaD, turma 2009, demonstrando que o 
curso proporcionou, aos estudantes, melhoria na vida profissional e pessoal dos sujeitos pesquisados.

Para fechar os artigos do dossiê, Inés Martins (da Espanha) e Juliana Guimarães Faria (do Brasil), apresentam o estudo "Cine, representación social y educación", com base em análise do cinema enquanto veículo de comunicação e sua linguagem, trabalham a ideia de seu uso como recurso educativo em práticas pedagógicas, apoiando a formação de sujeitos críticos e ativos em seu contexto social.

Frente às diferentes pesquisas e estudos, esperamos que os trabalhos aqui publicados possam contribuir para os leitores, autores e demais interessados na temática no que diz respeito às tendências e práticas apresentadas para o avanço de novos conhecimentos e reflexões que visem à formação humana e digital das pessoas, com justiça social. Do mesmo modo, considerando as diferentes abordagens e lugares dos pesquisadores que publicam no dossiê, buscou-se ampliar discussões que estendessem o repertório de análises sobre a EaD, conformando outras e novas posibilidades de debates.

Ótima leitura a tod@s!

\section{REFERÊNCIAS}

ALONSO, K. M. A expansão do Ensino Superior no Brasil e a EaD: dinâmicas e lugares. Educação \& Sociedade, Campinas, SP, v. 31, n. 113, p. 1319-35, out./dez. 2010.

ALONSO, K. M. A EaD no Brasil: sobre (des)caminhos em sua instauração. Educar em Revista, Curitiba, n. especial 4, p. 37-52, 2014 . Disponível em: http://www.scielo.br/ scielo.php?script=sci_arttext\&pid=S0104-40602014000800037\&lng=en\&nrm=iso. Acesso em: 18 jun. 2019.

DOURADO, L. F. Políticas e gestão da Educação Superior a Distância: novos marcos regulatórios? Educação \& Sociedade, Campinas, SP, v. 29, n. 104- Especial, p. 891-917, out. 2008.

HAFEEZ, A.; GUJJAR, A. A.; NOREEN, Z. Demanding need of growing technologies in distance learning system. Turkish Online Journal of Distance Education, v. 15, n. 4, p. 170-80, out. 2014. Disponível em: https://eric.ed.gov/?id=EJ1044212. Acesso em: 10 jan. 2019. 
Apresentação do Dossiê "Educação a Distância (EaD) e o uso das tecnologias na educação - qualidade, tendências e práticas"

LIMA, D. C. B. P.; FARIA, J. G.; DESIDERIO, M. Políticas e financiamento do ensino superior público no Brasil e as condições do trabalho docente a distância. In: TOSCHI, M. S. (Org.). Docência nos ambientes virtuais de aprendizagem - múltiplas visões. Anápolis, GO: Universidade Estadual de Goiás, 2013.

PEIXOTO, J. A concepção de dispositivos pedagógicos que integrem as TIC. Inter-Ação, Goiânia, UFG, v. 34, n. 1, p. 89-104, jan./jun. 2009.

RAJESH, M. Revolution in communication technologies: impact on distance education. Turkish Online Journal of Distance Education, v. 16, n. 1, p. 62-88, jan. 2015. Disponível em: https://files.eric.ed.gov/fulltext/EJ1092855.pdf. Acesso em: 10 jan. 2019.

SHERMAN, W. H.; CRUM, K. S.; BEATY, D. M. Perspectives on distance technology in leadership education: transfer, meaning and change. Journal of Research on Leadership Education, v. 5, n. 13, p. 580-610, 2010. Disponível em: https://files.eric.ed.gov/fulltext/ EJ913588.pdf. Acesso em: 10 jan. 2019.

ZAWACHI-RICHTER, O.; BACKER, E. M.; VOGT, S. Review of Distance Education Research (2000 to 2008): analysis of research areas, methods, and autorships patterns. The International Review of Research in Open and Distance Education, v. 10, n. 6, 2009.

\section{Sobre as organizadoras do Dossiê:}

Daniela da Costa Britto Pereira Lima: Professora Adjunta da Universidade Federal de Goiás no Curso de Pedagogia e Professora do Programa de Pós-Graduação em Educação (PPGE/UFG). Editora Chefe da Revista UFG, membro do conselho editorial da Revista Brasileira de Política e Administração da Educação (RBPAE), membro do Conselho Editorial da Revista Revelli (UEG), da Revista Exitus (UFOPA) e da Revista Série-Estudos da UCDB. Líder do Grupo de Pesquisa em Tecnologias e Educação a Distância (GEaD/UFG/DGP-CNPq). E-mail: daniela_lima@ufg.br, Orcid: http://orcid.org/0000-0002-1075-2113

Kátia Morosov Alonso: Professora associada da Universidade Federal de Mato Grosso (UFMT). Docente do Programa de Pós-Graduação em Educação- PPGE do Instituto de Educação da UFMT. Líder do Grupo de Pesquisa Laboratório de Estudos Sobre Tecnologias da Informação e Comunicação na Educação- LêTECE.

E-mail: katia.ufmt@gmail.com, Orcid: http://orcid.org/0000-0002-7125-664X 
